\title{
Magnetic Behavior of Trinuclear Vanadium(II)-Diamine Complexes. Part 2. Large Intramolecular Antiferromagnetic Exchange Interactions in a Triangular Unit
}

\author{
Ali Bayri, ${ }^{1,3}$ and Mustafa Sulu
}

ERRATUM TO: JOURNAL OF INORGANIC AND ORGANOMETALLIC POLYMERS AND MATERIALS DOI: 10.1007/s10904-006-9036-9

The submitted and accepted dates for this paper were inadvertently omitted. The dates are as follows:

Submitted October 28, 2005; accepted November 17, 2005

The online version of the original article can be found at: http:/ dx.doi.org/10.1007/s10904-006-9036-9

${ }^{1}$ Department of Physics, Arts and Science Faculty, Inonu University, 44069, Malatya, Turkey.

2 Department of Chemistry, Arts and Science Faculty, Inonu University, 44069, Malatya, Turkey.

3 To whom correspondence should be addressed.

E-mail: abayri@inonu.edu.tr 